\title{
The Role of Fibroblast Growth Factor 19 in Hepatocellular Carcinoma
}

\author{
Zhongguang Chen, ${ }^{*}$ Lili Jiang, ${ }^{\dagger}$ Lifan Liang, ${ }^{\ddagger}$ Kelly Koral, ${ }^{\S}$ Qian Zhang, ${ }^{\llbracket}$ Lei Zhao, ${ }^{\Uparrow}$ Songjian Lu, ${ }^{\ddagger}$ and Junyan Tao
}

From the Department of Pharmacy, * Central Hospital of Linyi, Yishui, Shandong, P.R. China; the Ultrasound Medical Department, ${ }^{\dagger}$ Jinan Central Hospital Affiliated to Shandong University, Jinan, P.R. China; the Departments of Biomedical Informatics ${ }^{\ddagger}$ and Pathology, ${ }^{\S}$ University of Pittsburgh, Pittsburgh, Pennsylvania; and the Department of Infectious Diseases, "Union Hospital, Tongji Medical College, Huazhong University of Science and Technology, Wuhan, P.R. China

Accepted for publication April 22, 2021.

Address correspondence to Songjian Lu, Ph.D. or Junyan Tao, Ph.D., University of Pittsburgh School of Medicine, 200 Lothrop St, S-432 BST, Pittsburgh, PA 15261. E-mail: songjian@pitt.edu or jut24@ pitt.edu.

\begin{abstract}
Hepatocellular carcinoma (HCC) is the fifth most common type of cancer and the third leading cause of cancer-related deaths worldwide. Liver resection or liver transplantation is the most effective therapy for HCC because drugs approved by the US Food and Drug Administration to treat patients with unresectable HCC have an unfavorable overall survival rate. Therefore, the development of biomarkers for early diagnosis and effective therapy strategies are still necessary to improve patient outcomes. Fibroblast growth factor (FGF) 19 was amplified in patients with HCC from various studies, including patients from The Cancer Genome Atlas. FGF19 plays a syngeneic function with other signaling pathways in primary liver cancer development, such as epidermal growth factor receptor, Wnt/ $\beta$-catenin, the endoplasmic reticulum-related signaling pathway, STAT3/IL-6, RAS, and extracellular signal-regulated protein kinase, among others. The current review presents a comprehensive description of the FGF19 signaling pathway involved in liver cancer development. The use of big data and bioinformatic analysis can provide useful clues for further studies of the FGF19 pathway in HCC, including its application as a biomarker, targeted therapy, and combination therapy strategies. (Am J Pathol 2021, 191: 1180-1192; https://doi.org/10.1016/j.ajpath.2021.04.014)
\end{abstract}

Hepatocellular carcinoma (HCC) is the fifth most common type of cancer and is the third leading cause of cancerrelated deaths worldwide. In 2018, the World Health Organization predicted that approximately $83 \%$ of the 841,000 new patients with liver cancer are from Eastern Asia. According to the American Cancer Society, there will be 42,230 newly diagnosed cases and 30,230 deaths from HCC and intrahepatic bile duct cancer in the United States in 2021 (https://cancerstatisticscenter.cancer.org, last accessed February 28, 2021). Currently, the most effective therapy for HCC is liver resection or transplantation. However, recurrence after surgical resection remains a major concern. Treatment options for HCC are limited and generally ineffective. ${ }^{1}$ Sorafenib and regorafenib are currently the most effective drugs for patients with unresectable HCC. ${ }^{2,3}$ Drugs recently approved by the US Food and Drug Administration, such as nivolumab, stivarga, ramucirumab, cabozantinib, and lenvatinib, the combination of target chemotherapy, and immunity check point inhibitors are now available. However, because of limited efficacy and poor 3-month survival rates for patients with HCC taking sorafenib or regorafenib, surgical resection or liver transplantation have been preferred as curative treatments for early-stage HCC. The molecular mechanisms underlying HCC development remain poorly understood, and there is an urgent need to develop novel therapeutics against this deadly malignant neoplasm.

Among various well-known and newly discovered oncogenes related to HCC, fibroblast growth factor FGF) 19 is overexpressed in HCC. ${ }^{4}$ The current review provides a detailed overview on the FGF19 signaling pathways in HCC development, including its role as a biomarker in various

Supported by NIH grant R00LM011673 (S.J.L.) and National Cancer Institute grant P30CA047904 (S.J.L.).

Disclosures: None declared. 
animal models as well as the potential clinical application of targeting FGF19 as a novel therapeutic option. Bioinformatics software and a data platform were used to help in the data mining of studies on the clinical relevance of FGF19 in HCC.

\section{FGF19 as a Biomarker in HCC}

The FGF family has $>20$ different members, including paracrine FGF ( $F G F 1 / 2$ subfamily, FGF4/5/6, FGF8/17/ 18, $F G F 3 / 7 / 10 / 22, F G F 9 / 16 / 20$ subfamily), intracrine FGF (FGF11/12/13/14 subfamily), and endocrine FGF (FGF19/21/23 subfamily). ${ }^{5}$ These growth factors have a variety of functions, which include regulating metabolism, cell proliferation, differentiation, and survival. Although some studies have found that FGF19 is also involved in hepatoblastoma ${ }^{6}$ and cholangiocarcinoma, ${ }^{7}$ this review focuses on $\mathrm{HCC}$ because it covers $>85 \%$ of primary liver cancer.

The activity of FGF19 is predominantly fibroblast growth factor receptor (FGFR) 4-dependent, although a few studies indicate its role in an FGFR4-independent manner. Structure and function analysis shows that the Nterminal of FGF19 is important for FGFR activity and biding, and the c-terminal of FGF19 is responsible for the binding to $\beta$-klotho.

Approximately $7 \%$ of patients with HCC from The Cancer Genome Atlas (TCGA) database (25 of 353 patient samples) have a high copy number of FGF19. Patients with a higher expression of FGF19 in HCC had shorter median survival compared with a low-expression cohort (54.1 versus 108.6 months), although no significant difference was found between the two cohorts and no significant difference in the overall survival (OS) between those with high FGF19 expression and those with low FGF19 expression (http://kmplot.com/analysis, last accessed April 2, 2021) (Figure 1A). Male patients with alcohol risk factors have lower OS when compared with those with higher or lower FGF19 expression (20 versus 47.4 months, $P=0.016$ ) (Figure 1B). However, in the nonalcoholic liver disease-related HCC cohort, patients with $\mathrm{HCC}$ with higher expression of FGF19 had better OS when compared with patients with HCC with lower FGF19 expression (71 versus 49.7 months, $P=0.096$ ). These results indicate the dual and complicated role of FGF19 in HCC development, and point towards screening of potential risk factors before adjusting FGF19 expression for HCC treatment. These results were also verified in animal experiments in nonalcoholic fatty liver disease. ${ }^{8}$ Meanwhile, patients with stage 1 HCC with higher FGF19 expression had lower OS compared with those with lower FGF-19 expression (OS data are not available, $P=0.049$ ). When compared with patients with stage I and II HCC from TCGA, higher fgf19 expression groups had lower median OS (81.9 versus 108.6 months, $P=0.079$ ). Although no correlation was found in the advanced stage HCC group, these results point towards the use of FGF19 as an early-stage biomarker and target therapy for HCC.

Because of heterozygous and complicated risk factors of HCC development, fewer single genes could be used to predict HCC survival. However, they were sufficient to predict the outcome combined with various risk factors and molecular biology events behind the diseases progress. In addition, the diagnosis of HCC at an early stage is important for therapy outcome, and the development of new efficient biomarkers for HCC diagnosis has been the goal of bench and clinical researchers for many years. In particular, with the development of high-throughput sequencing techniques, new molecular biomarkers have been discovered from the tissue or blood of patients with HCC. One study found that the expression of FGF19 in the serum could be used as a biomarker to detect HCC and predict the treatment outcome. ${ }^{9}$ FGF19 is up-regulated at both the mRNA and protein levels, and can be used as a biomarker for a specific subtype of HCC, depending on the cause of the disease. ${ }^{10}$ In addition, FGF19 copy number may be an additional predictor of response to sorafenib in combination with FGF3/FGF4 amplification ${ }^{11}$ because FGF-3/FGF-4 amplification serves as a predictor of response to sorafenib treatment in patients with HCC. ${ }^{12}$

\section{Role of FGF19 in Tumorigenesis in Various Mouse Models}

Aberrant FGF/FGFR signaling plays a role in tumorigenesis as indicated by various mouse genetic models and human genetic studies. ${ }^{13-15}$ FGF19 plays an important role in liver regeneration after acetaminophen-induced liver injury, ${ }^{16}$ as well as reducing liver injury in multidrug resistance 2-deficient mice. ${ }^{17}$

Eight to ten-month old FGF19 transgenic mice spontaneously develop HCC, and 2 to 4-month old transgenic mice have remarkably higher levels of 5-bromo-2'-deoxyuridine-labeled hepatocytes than those in the age-matched wild-type mice. ${ }^{18}$ Furthermore, recombinant FGF19 protein also induced a significantly higher 5-bromo-2'-deoxyuridine-labeling index in healthy mice injected with endogenous FGF19. ${ }^{18,19}$

The mouse ortholog of human FGF19 is Fgfl5; however, these two hormones exert different effects, depending on the system being studied. Zhou et al ${ }^{17,20}$ found that both Fgf15 and FGF19 hormones repressed bile acid (BA) synthesis. Because mouse FGF15 and human FGF19 share approximately $50 \%$ amino acid identity, they exhibit fundamentally different biological activities in mice. However rodent models can be used to evaluate the safety of farnesoid X receptor (FXR) activators or FGF19 inhibitors. Murine Fgf15 lacked the protective effects characteristic of human FGF19 in db/db mice. In addition, unlike FGF19, Fgf15 does not induce $\mathrm{HCC}$ in $\mathrm{db} / \mathrm{db}$, diet-induced obese, and 


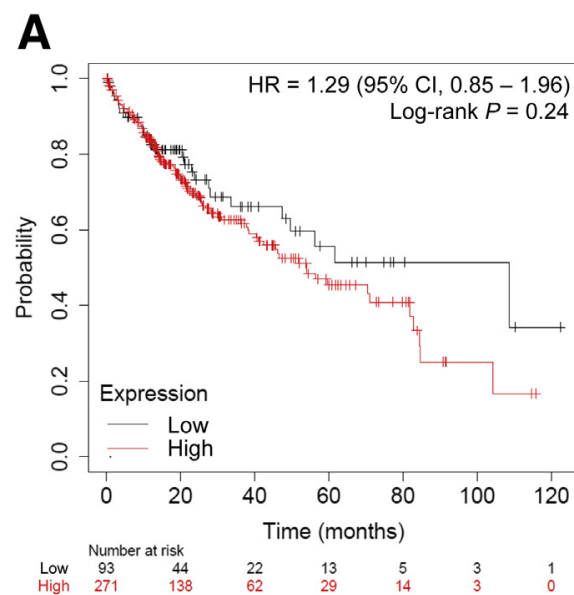

All

B

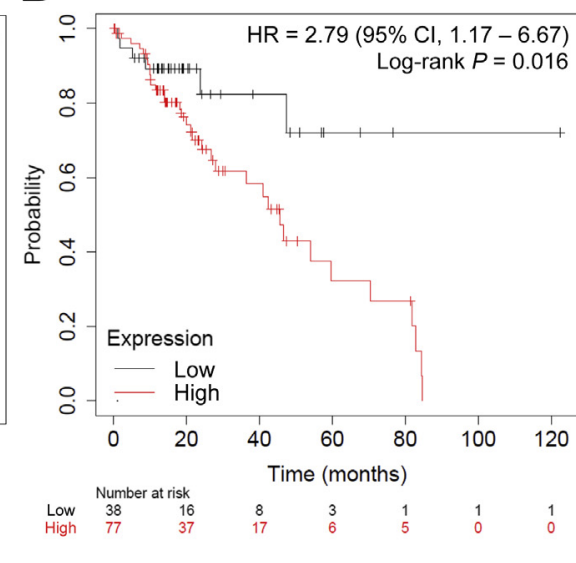

Alcohol risk
C

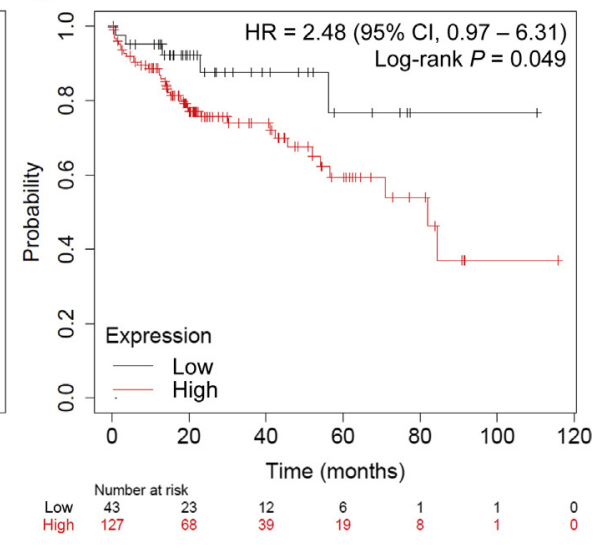

Stage 1

Figure 1 Fibroblast growth factor 19 (FGF19) amplification in liver cancer and correlation of its expression with survival ratio. A: No significant difference was found in the overall survival between high FGF19 expression and low FGF19 expression group [hazard ratio (HR) $=1.29 ; P=0.24$ ). B: Patients with higher FGF19 expression had a lower survival ratio when analyzed by alcohol risk factors $(P=0.016)$. C: For patients with stage 1 hepatocellular carcinoma, the higher FGF19 expression group had a lower survival ratio $(P=0.049)$.

multidrug resistance 2-deficient mice models of metabolic diseases. $^{20}$

Humans express FGF19 in the liver and the intestine, but mice express Fgf15 only in the intestine. Livers of mice repopulated with human hepatocytes grow larger than normal in healthy mice because the human hepatocytes do not recognize Fgf15 produced in mouse intestine, resulting in promoting BA synthesis and BA pool in mice. However, in FGF19 transgenic mice, the transplanted human hepatocytes grow to normal size. ${ }^{21}$ These results indicate that mouse Fgf15 does not bind to human FGFR4, whereas FGF19 overexpression in mice liver is active, and FGF19 binds to mouse Fgfr4 ( $\mathrm{Z}$. Chen et al, unpublished data). Additional models are needed to explore the mechanisms behind these differences. Studies in translational medicine study can be used to interpret the results from mice experiments.

\section{FGF19 Mechanisms for HCC Improvement}

Under normal conditions, FGF19/15 regulates liver BA and lipid metabolism, in addition to playing a vital role in liver regeneration after partial hepatectomy or acetaminophen-induced injury in mice. ${ }^{16}$ Amplification of FGF19 stimulates hepatocellular protein synthesis and proliferation. Although the downstream signaling pathways that mediate FGF19-dependent tumorigenesis are still unclear, extracellular signal-regulated protein kinase (ERK) and $\beta$-catenin have been implicated in hepatocyte proliferation, survival, migration and invasion, as well as angiogenesis. ${ }^{22}$ Therefore, the current review provides an update of the recent studies on the FGF19 pathway in primary liver cancer.
Wnt/ $\beta$-Catenin as a Downstream Target Gene in FGF19Amplified HCC

$\beta$-Catenin is regulated by FGF19 during epithelialmesenchymal transition (EMT) in HCC cells, ${ }^{23}$ and the expression of FGF19 is significantly increased and negatively associated with E-cadherin expression in HCC tissues and cell lines. Teng et al $^{24}$ showed that FGF19 regulates glycogen synthase kinase $3 \beta$ (GSK3 $\beta$ ) to activate the stressregulated transcription factor called nuclear factor (erythroid-derived 2)-like 2 (Nrf2 or NFE2L2) in several HCC cells. Therefore, the FGFR4-GSK3 $\beta$-Nrf2 signaling cascade could be a potential therapeutic candidate for HCC treatment. However, FGF19 amplification is mutually exclusive to $\beta$-catenin and AXIN1 mutations in a subtype of patients with $\mathrm{HCC},{ }^{25}$ demonstrating that $\beta$-catenin can play a dependent or independent role in HCC with FGF19 amplification, depending on other risk factors.

\section{ER Stress Involved in FGF19 Amplification in HCC}

Endoplasmic reticulum (ER) stress promotes tumor cell escape from immunosurveillance, ${ }^{26}$ is associated with liver cancer and other liver diseases, ${ }^{27,28}$ and is involved in diethylnitrosamine-induced HCC in rats. ${ }^{29}$ FGF19 overexpression regulates ER stress and tumor cell proliferation via activation of the FGFR4-GS3K $\beta$-Nrf2 signaling pathway. ${ }^{24}$

\section{Stat3/IL-6 Activation in FGF19-Induced HCC}

The IL-6/STAT3 axis is involved in FGF19-driven HCC in mice. ${ }^{30}$ FGF19 increases IL-6 production in the liver microenvironment followed by STAT3 activation in 
hepatocytes. Inhibition of STAT3, IL-6, or JAK expression abolishes FGF19-induced tumorigenesis. However, the regulatory functions of FGF19 in BA, glucose, and energy metabolism remain intact.

\section{Activation of Ras and ERK Signaling Pathway in FGF19-Amplified HCC}

Ras and ERK play key roles in HCC development ${ }^{31}$ and can be activated by FGF19. ${ }^{32,33}$ FGF19 is the upstream stimulus for the Ras-ERK-Mnk1 signaling cascade, leading to activation of phosphorylation of eukaryotic initiation factor 4B and eukaryotic initiation factors on Ser209, ${ }^{34}$ which can mediate mRNA binding to the ribosome to promote translation initiation. Exogenous FGF19 also increases the phosphorylation of ERK1/ERK2 and upregulates phosphorylation of Ser235 and Ser236 of the ribosomal protein $\mathrm{S} 6(\mathrm{rpS6}$ ), which is involved in protein synthesis in the liver of mice fasted overnight ${ }^{34}$ (Figure 2A).

\section{EGFR Signaling Pathway in HCC Induced by FGF19 Activation}

A recent study found that the epidermal growth factor receptor (EGFR) ligand amphiregulin (AR) plays a central role in HCC proliferation, survival, and drug resistance. AR expression is frequently up-regulated in HCC tissues and cells. ${ }^{35}$ Latasa et $\mathrm{al}^{36}$ found that FGF19 induced AR expression through activation of $\beta$-catenin signaling in HCC, resulting in up-regulation of cyclin D1 (CCND1). These results were used to estimate the network of FGF19 and EGFR in patients with HCC in TCGA data sets (liver hepatocellular carcinoma, TCGA, PanCancer Atlas, 372 total samples) through cBioPortal (https://www.cbioportal. org, last accessed April 6, 2021); the signal pathway involved in FGF19-EGFR, including EGFR, FGFR4, neurotrophic receptor tyrosine kinase 1 (NTRK1), Ki-ras2 Kirsten rat sarcoma viral oncogene homolog, Ras like without CAAX 1, Raf-lproto-oncogene, serine/threonine kinase, and mitogen-activated protein kinase (MAPK1); and the network of FGF19 and EGFR with LENS (https:// hagrid.dbmi.pitt.edu/LENS, April 6, 2021), a web-based tool for predicting the network of protein-protein interactions through one or two lists of genes of interest. ${ }^{37}$ The results indicate that FGF19 and EGFR crosstalk through signal pathways including EGFR-RAF1-PDLIM2-FGFR4FGF19, EGFR-ERRFI1-FGFR4-FGF19, EGFR-STAT1FGFR4-FGF19, EGFR-(NTRK1)-PLCG1-FGFR4-FGF19, and EGFR-(NTRK1)-(MAPK1)-STAT3-FGFR4-FGF19 (only the connecting nodes are shown) (Figure 2B). FGF19 and EGFR signaling can both contribute to HCC development and progression through direct and indirect shared signaling pathways.

\section{Bioinformatic Analysis to Determine the Secondary Hit Involved in FGF19 Amplification-Induced Primary Liver Cancer}

In HCC models generated in mice using sleeping beauty transposon technology, one oncogene or tumor suppressor gene perturbation is usually not sufficient to induce liver cancer development, and additional gene changes are required to induce liver cancer. The understanding of the progression of FGF19-amplified HCC would be improved by determining the secondary hit and molecular modification events necessary for liver carcinogenesis.

\section{Impact of FGF19 Amplification on Chromatin Accessibility}

As a member of the FGF family, FGF19 may direct changes in higher-order chromatin organization. ${ }^{38}$ However, direct evidence of a role of FGF19 in chromatin organization has not been found. The processed assay for transposaseaccessible chromatin was downloaded using sequencing (ATAC-seq) data on tumor samples from the Xena browser, along with the copy number variation status of FGF19 in corresponding samples, to determine whether FGF19 plays a role in accessibility. Pearson correlation was captured between FGF19 copy number variation status and ATAC-seq binding signals. Some of the peaks have a strong correlation with FGF19, thereby supporting the theory that FGF19 can direct changes in chromatin organization (Figure 3A). Notably, some of the peaks were located near the same genes, such as MYEOV, FGF4, and RPI1. Peaks with $P$ values smaller than $10^{-1}$ were selected and merged on the gene level. Ninety nine genes were input in the chromatin immunoprecipitation sequencing (ChIP-seq) enrichment analysis ${ }^{39}$ on EnrichR, ${ }^{40}$ using the transcription factor ChIP-seq with $P<0.01 .^{41}$ FGF19 can regulate hepatic glucose metabolism by inhibiting CBP. ${ }^{42}$ The relationship of FGF19 with other transcription factors, including AHR, RUNX1, and RUNX2, is also supported by the literature. ${ }^{43,44}$ However, this relationship could be reversed in which the transcription factors regulate FGF19 expression. For example, a master transcriptional activator, SREBP2, is found to negatively regulate FGF19 in intestinal cells. ${ }^{45}$ Although ERG and ARNT were well studied as tumor drivers or protectors, there is no evidence of their functional relationship with FGF19. FGF19 can influence chromatin assembly, which can affect the development and progression of HCC; however, additional studies are warranted to determine the specific transcription factors involved in this process.

\section{Finding HCC Driver Partners for FGF19}

Because manipulating FGF19 alone is not sufficient to induce HCC development, modifying an additional HCC 

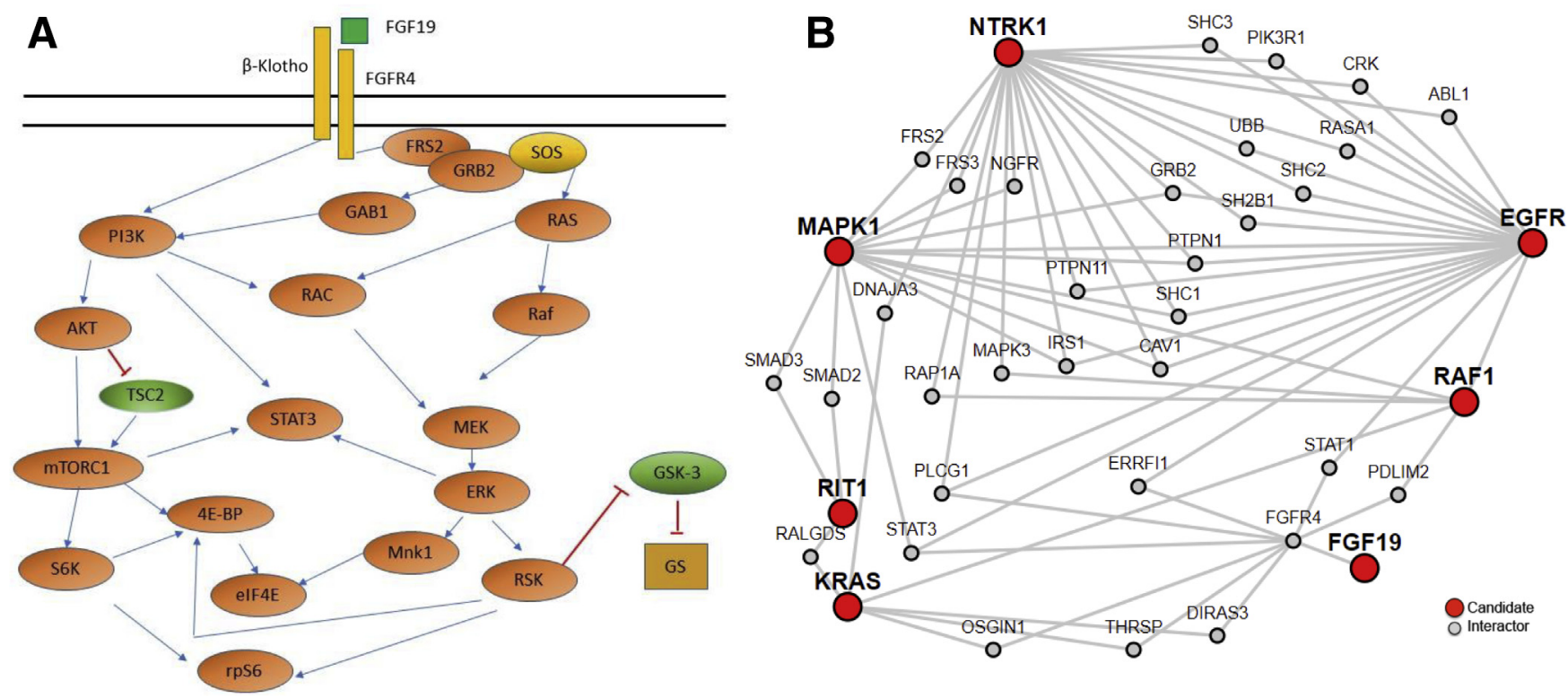

Figure 2 Molecular mechanisms of fibroblast growth factor 19 (FGF19) in liver cancer development. A: Signaling pathways related to FGF19 activation in liver cancer development. Binding of FGF19 to its co-receptor $\beta$-Klotho and FGFR4, FGF19-FGFR4 activated downstream signaling, including phosphatidylinositol 3-kinase (PI3K)/AKT/mechanistic target of rapamycin (mTOR), RAS/extracellular signal-regulated protein kinase (ERK) pathway, leading to cell growth and proliferation, and had an effect on protein and glycogen synthesis, which are often activated in liver cancer. The blue arrow indicates activation, and the red blunt line indicates inhibition. B: The network between FGF19 and EGFR was analyzed with LENS. The nodes in the network were taken from the pathway involved in FGF19 and EGFR in the patient analysis with cBioPortal (https://www.cbioportal.org): EGFR-RAF1-PDLIM2-FGFR4-FGF19, EGFR-ERRFI1-FGFR4-FGF19, EGFR-STAT1-FGFR4-FGF19, EGFR(NTRK1)-PLCG1-FGFR4-FGF19, EGFR-(NTRK1)-(MAPK1)-STAT3-FGFR4-FGF19 (only the connecting nodes discussed here are shown). ABL1, ABL proto-oncogene 1; CAV1, caveolin 1; DIRAS3, DIRAS family GTPase 3; eIF4B, eukaryotic initiation factor 4B; eIF4E, eukaryotic initiation factor 4E; ERRFI1, ERBB receptor feedback inhibitor 1; FRS, fibroblast growth factor receptor substrate; GAB1, GRB2 associated binding protein 1; GRB2, growth factor receptor bound protein 2; IRS1, Insulin Receptor Substrate 1; KRAS, Ki-ras2 Kirsten rat sarcoma viral oncogene homolog; MAPK1, mitogen-activated protein kinase; Mnk1, ;mTORC1, mammalian target of rapamycin complex 1;NTRK1, neurotrophic receptor tyrosine kinase 1; 0SGIN1, oxidative stress induced growth inhibitor 1; PIK3R1, phosphoinositide-3-kinase regulatory subunit 1; PLCG1, phospholipase C gamma 1; PTPN1, protein tyrosine phosphatase non-receptor type 1; RAC, Rac family small GTPase; RAF, Raf-1protooncogene, serine/threonine kinase; RALGDS, Ral Guanine Nucleotide Dissociation Stimulator; RAP1A, Ras-related protein Rap-1A; RASA1, RAS P21 protein activator 1; RIT1, Ras like without CAAX 1; rpS6, ribosomal protein S6; RSK, resistant to spore killer; S6K, ribosomal protein S6 kinase B1; SH2B1, SH2B adaptor protein 1; SHC3, SHC adaptor protein 3; SOS, son of sevenless; THRSP, thyroid hormone responsive; TSC2, TSC complex subunit 2; UBB, ubiquitin B.

driver gene, called the driver partner of FGF19, is needed to induce oncogenesis in primary cells. For instance, overexpressing both FGF19 and Met induced HCC development in mice, which was not seen if only one of these genes was overexpressed (Z. Chen et al, unpublished data). Therefore, finding driver partners for FGF19 is crucial and needs to be addressed. If somatic genomic alterations (SGAs) of two genes/drivers are necessary or sufficient to cause HCC development, then the SGAs of these two genes should cooccur often in HCC tumors. TCGA data cohort has SGAs, including somatic mutation and copy number alteration data for approximately 360 HCC tumors, ${ }^{46}$ which provides useful information to find driver partner candidates with high-alteration co-occurrences with FGF19. Once the genes of interest are found, then the cBioPortal is a convenient tool to check their SGA co-occurrence with FGF $19 .{ }^{47}$ However, the high SGA co-occurrences of two genes are not always related to tumor development. Because copy number alterations usually occur from DNA segment copy and paste (gene amplification) or deletion (gene deletion), SGAs of neighboring genes may co-occur often, but are usually not related to HCC development. For example, SGAs of FGF19 and CCND1 are often co-amplified in TCGA HCC tumors because they are neighboring genes on chromosome 11 (Figure 3B). Sawey et $\mathrm{al}^{48}$ found that FGF19 and its neighbor CCND1 had high copy numbers in patients with HCC based on a clinical screening study; therefore, FGF19 and CCND1 could be an effective biomarker for patient sensitivity to anti-FGF19 treatment. However, simultaneously overexpressing FGF19 and CCND1 in mouse liver with a sleeping beauty transposon system via hydrodynamic tail vein injection ${ }^{49}$ showed no tumor nodules at 30 weeks after tail vein injection (Z. Chen et al, unpublished data). On the basis of the current experimental results, the network between FGF19 and CCND1 was analyzed for a potential genetic link between them. First, using the network map from the cBioPortal data set, STAT3 was found as a gene linking FGF19 and CCND1. At the same time, the crosstalk between these pathways was explored by using the interactome software known as LENS. More than 30 genes were involved in CCND1 activity, but the shortest path between FGF19 and the CCND1 network was FGF19-FGFR4STAT3-CCND1 (Figure 3C). These results indicate that STAT3 might be the second tumorigenesis hit to FGF19 or 
A
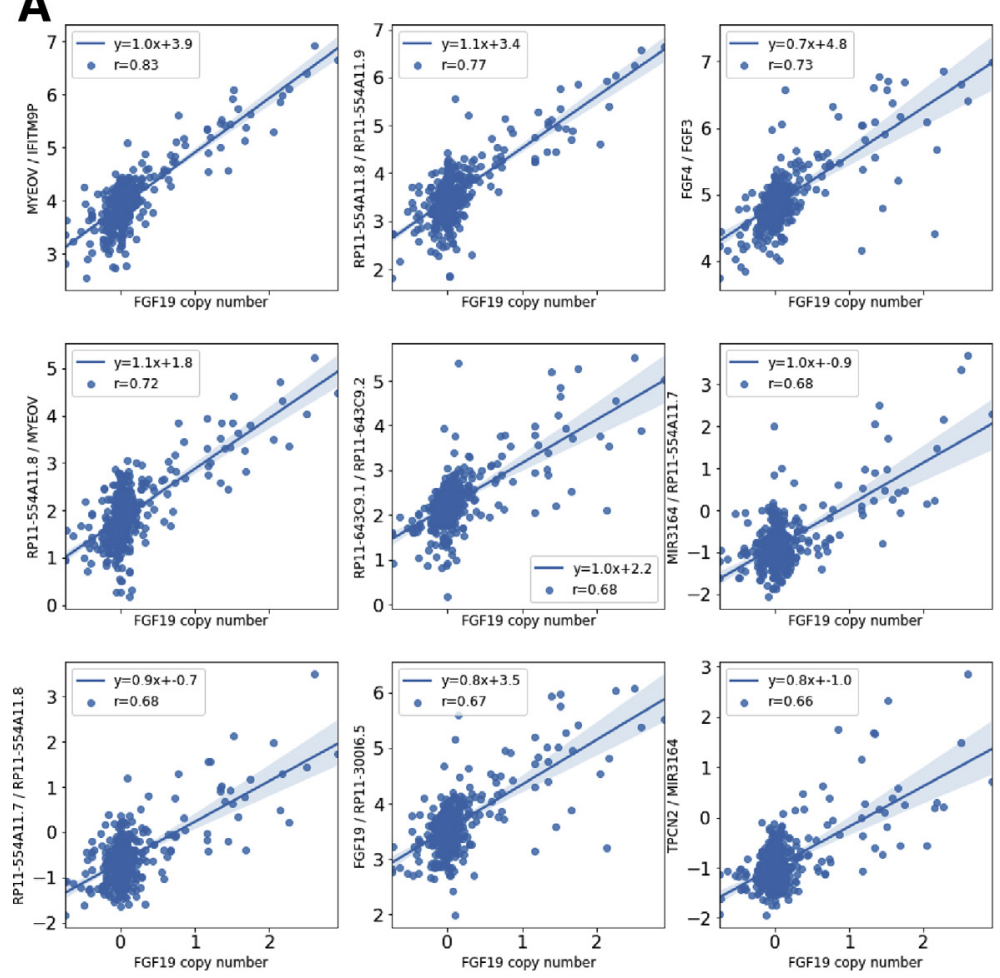

B

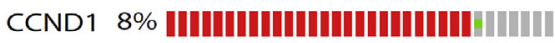

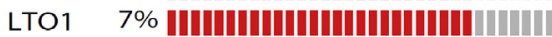

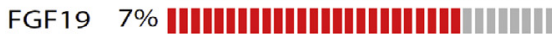

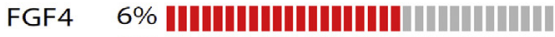

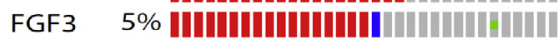
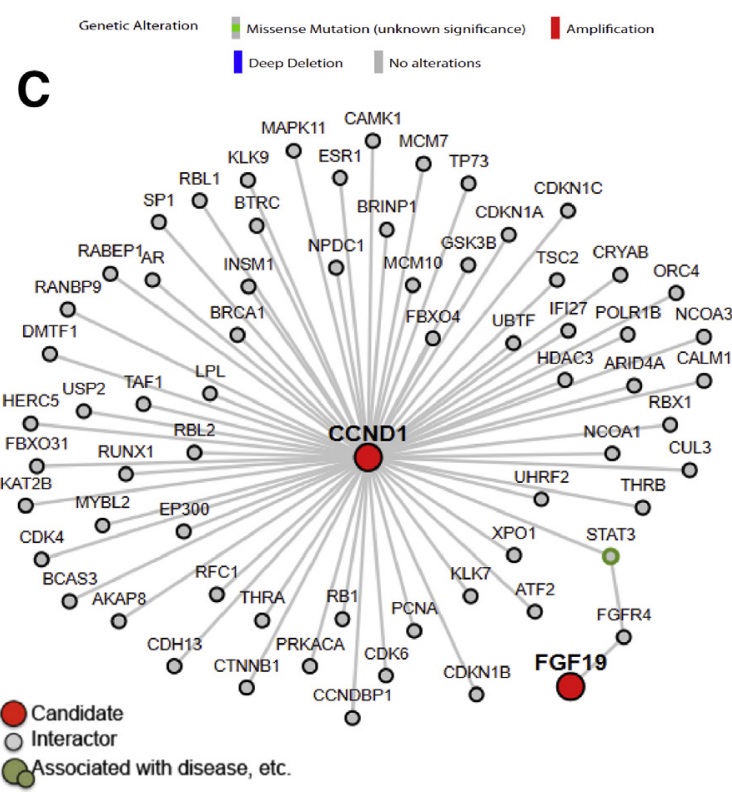

Figure 3 Bioinformatic analysis of fibroblast growth factor 19 (FGF19) and its partner in liver cancer development. A: Pearson correlation between FGF19 copy number variation status and assay for transposase-accessible chromatin using sequencing binding signals analysis. The blue shaded areas around the line indicate standard deviation. B: FGF19 and its neighbor genes were often coamplified in The Cancer Genome Atlas hepatocellular carcinoma (HCC) tumors (the figure is generated from cBioProtal, https://www. cbioportal.org. C: Network analysis between FGF19 and cyclin D1 (CCND1) by LENS. Approximately $>30$ genes were involved in CCND1 activity, but the shortest path between the FGF19 and CCND1 network was FGF19-FGFR4-STAT3-CCND1. STAT3 might be the secondary hit to FGF19 tumorigenesis role in HCC development. Red circles indicate candidate; gray circles, interactor.

CCND1, and neighboring genes of FGF19 should be excluded when searching for its driver partners.

SGAs of an HCC driver affect cellular behavior by perturbing a signaling pathway, which includes the driver gene as a member. Hence, SGAs of FGF19's driver partner may not overlap significantly with those of FGF19 but overlap significantly with SGAs of another gene on the same signaling pathway, which includes FGF19 as a member. In this case, the information of SGA co-occurrences is not helpful to find the driver partners. One way to address this challenge is to search for signaling pathways in which the SGAs of the pathways and FGF19 alterations co-occur frequently. Different computational models and algorithms have been developed to search for novel signaling pathways using big omics data and TCGA data cohort. ${ }^{50}$ The mutual exclusivity of SGAs in tumors is one of the most important properties that has been heavily relied on to search for pathways. ${ }^{51-53}$ Many network-based models consider functional relations or protein-protein interactions among members in the signaling pathways. ${ }^{41}$ The models that consider the causal relations between SGAs that perturb pathways and expression changes of genes regulated by the perturbed pathways are also very important in accurately identifying signaling networks. ${ }^{52,54,55}$ The various techniques of finding pathways altered in HCC can greatly expand the number of possible candidates for new driver partners of FGF19.

\section{Comprehensive Therapy Strategies in FGF19- Amplified HCC}

FGF19 may be a new target for the treatment of HCC. However, large clinical trials studying FGF19 in HCC are still needed. Deep mining of clinically relevant data to determine the role of FGF19 in HCC and fully understanding the complex molecular mechanisms of FGF19 can provide new opportunities for therapeutic strategies to treat advanced HCC.

\section{Targeting FGF19 or Its Receptor FGFR4 and Other Downstream Target Genes}

The FGF19/FGFR4/ßKL signaling pathway might be used for precision medicine strategies for treatment of a subset of patients with HCC with the FGF19 amplification signature (Figure 4). As the predominant FGFR expressed in hepatocytes, FGFR4, a well-known regulon of FGF19, ${ }^{4,23,56,57}$ is 


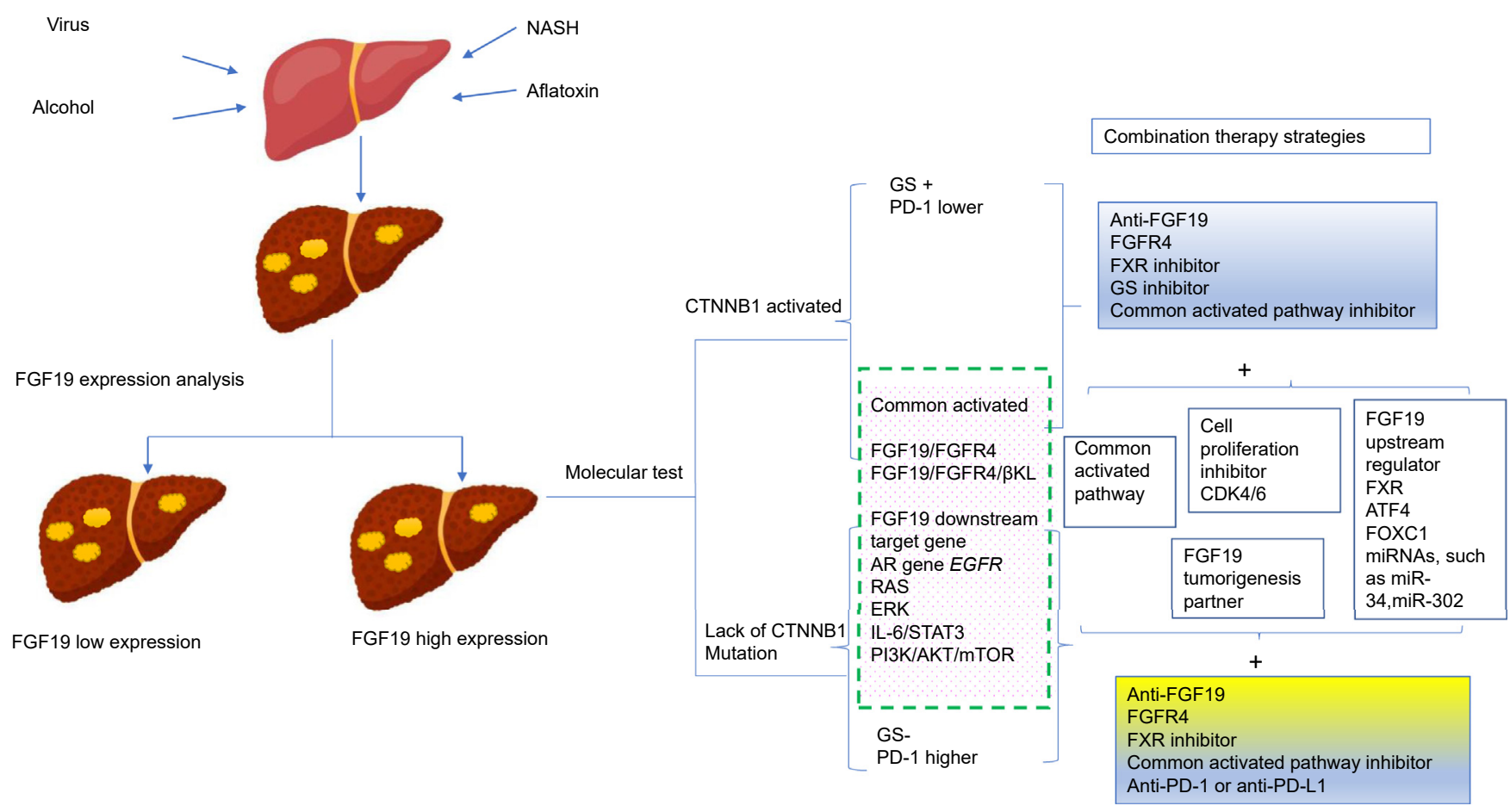

Figure 4 Combination therapy strategies based on the role of fibroblast growth factor 19 (FGF19) in hepatocellular carcinoma (HCC). Various risk factors, including virus (hepatitis B virus and hepatitis C virus), heavy alcohol use, nonalcoholic fatty liver disease (NASH), and aflatoxin B, can lead to HCC development. Screening of patients with HCC based on FGF19 expression level allows for patients to be separated into 2 subtypes: one group with low expression of glycogen synthase (GS)-positive (GS+) and programmed cell death 1 (PD-1) and the other group with high expression of GS-negative (GS-) and PD-1. Combination therapy strategies can then be used based on the molecular subtype by combining the FGF19 co-receptor $\beta$-Klotho and fibroblast growth factor receptor 4 (FGFR4). FGF19-FGFR4 downstream signaling inhibitor or upstream regulator inhibitors with the PD-1 inhibitor are activated in the GSpopulation. However, there is a need to combine with the PD- 1 inhibitor in the GS+ [ $\beta$-catenin (CTNNB1) activated] group. AR, amphiregulin; ATF4, activating transcription factor 4; $\beta K L$, $\beta$-klotho; ERK, extracellular signal-regulated protein kinase; FOXC1, forkhead box C1; FXR, farnesoid X receptor; PI3K, phosphatidylinositol 3-kinase; mTOR, mechanistic target of rapamycin; PD-L1, programmed cell death 1 ligand 1.

frequently overexpressed and involved in HCC development, ${ }^{58}$ promotes EMT, and contributes to sorafenib resistance. In addition, the activation of FGFR4 alone is sufficient to induce hepatocyte proliferation ${ }^{19,59}$ and is required for FGF19-induced hepatocyte proliferation. ${ }^{60}$ FGF19-induced EMT can be markedly attenuated when FGFR4 is knocked out; however, FGF19-induced EMT can not be abrogated when FGF19 is depleted in the presence of GSK3 $\beta$ inhibitors. ${ }^{23}$ This finding suggests that the FGFR4/ GSK3 $\beta / \beta$-catenin axis may play an important role in FGF19-induced EMT in HCC cells.

In a preclinical study, anti-FGF19 completely inhibited the development of liver tumors in FGF19 transgenic mice, and the inhibition of FGF19-dependent activation of FGFR4, fibroblast growth factor receptor substrate 2, ERK, and $\beta$-catenin was related to the efficacy of the antibody in this model. ${ }^{61}$ Meanwhile, more studies have shown FGFR4 to be a potentially useful therapeutical target for HCC. ${ }^{57}$ Knockdown of FGFR4 using siRNA was able to suppress $\alpha$-fetoprotein production in the liver cancer line $\mathrm{HuH} 7{ }^{58}$ Another study found that anti-FGF19 or FGFR4 antibodies are useful for the treatment of HCC. ${ }^{62}$ In an FGF19 transgenic mouse model, blocking FGFR4 inhibited the binding between FGF19 and FGFR4 and, subsequently, tumor development in mice. ${ }^{63}$ An FGFR4-specific inhibitor, BLU9931, was developed and demonstrated remarkable antitumor activity in a xenograft HCC mice model with FGF19 overexpression. To reduce the adverse effects of an FGF19/FGFR4 inhibitor on BA synthesis, an FGFR4 targeting antibody, U3-1784, was designed to inhibit FGF19induced carcinogenesis without affecting the synthesis of BA. This inhibitor had good anti-tumor effects on 10 different liver cancer models without invertible injury. ${ }^{64}$ Conversely, genetic deletion of FGFR4 in mice resulted in faster progression of diethylnitrosamine-accelerated HCC, indicating that FGFR4 may suppress hepatoma proliferation. ${ }^{65}$ Taken together, these findings indicate that the role of FGFR4 in HCC progression needs to be further investigated.

In a clinical trial study, BLU9931 had good therapeutic efficiency on one-third of patients with HCC and FGF19/ FGFR4 activation. ${ }^{66}$ A clinical relevance study found that lenvatinib could inhibit HCC development by targeting FGFR4 in vivo and in vitro, including in the FGF19 overexpressed HCC cell line Hep3B2.1-7. ${ }^{67}$ Another phase 1 trial with a selective oral FGFR4 inhibitor, fisogatinib (BLU-554), of 25 patients found an overall response rate of 17\% in FGF19-positive patients and 0\% in FGF19-negative 
patients. These results indicate that FGFR4 can be used as a targetable driver in FGF19-positive advanced HCC. ${ }^{68}$

Besides FGFR4, some downstream target genes of FGF19/FGFR4 can also be used for the treatment of FGF19amplified HCC. FGF19 regulates the activation of the small heterodimer partner (SHP) ${ }^{69,70}$ and may also impact mitochondrial efficiency through regulating GC- $1 \alpha .^{71}$ An additional function of FGF19 is regulating gene expression through metabolism, for example, by regulating BA through FXR and repressing PON1 expression. ${ }^{72}$ Increase in BA synthesis in response to high cholesterol leads to a negative feedback of FGF19 on BA secretion by inhibiting cholesterol $7 \alpha$-hydroxylase (CYP7A1) ${ }^{73}$ FGF19 can correct BA signaling defects to normalize BA synthesis, the BA pool, and liver size in mice. ${ }^{21}$ In addition, a nontumorigenic FGF19 analogue suppresses BA synthesis in mice to protect against hepatocarcinogenesis. ${ }^{74}$ Therefore, one of these additional signaling pathways can be targeted to treat HCC with an FGF19 amplification.

\section{Targeting Upstream Regulators of FGF19}

Another strategy to develop potential therapeutic targets for HCC would be to explore the upstream regulators of FGF19. It is well known that FGF19 is regulated by FXR in the gut-liver axis, ${ }^{75,76}$ which includes FXR-responsive elements in the FGF19 promoter region. ${ }^{77}$ Besides FXR, studies have also found that activating transcription factor 4 regulates FGF19 expression in the small intestine. ${ }^{78}$ Furthermore, additional evidence indicates that FOXC1 regulates the expression of FGF19. ${ }^{79}$ Therefore, many upstream regulators of FGF19 can be studied to determine if any are potential targets for novel HCC treatments.

miRNAs are potential candidates for liver cancer treatment because they play an important role in liver cancer development. $^{80}$ miR-34a down-regulates the FGF19 coreceptor $\beta \mathrm{KL}$ by binding to the $3^{\prime}$-UTR of $\beta \mathrm{KL}$ mRNA in vitro. Hepatic $\beta \mathrm{KL}$, ERK, and glycogen synthase decrease in response to adenoviral-mediated overexpression of miR-34a in mice. Therefore, the miR-34a//KL/FGF19 axis may present unique therapeutic targets for FGF19related human diseases, including metabolic disorders and cancer $^{81,82}$ (Figure 4).

\section{Integration Therapy Strategies with Combination Therapy of Anti-PD-1 and FGF19/FGF19 Signal Pathway Inhibitors}

The efficacy of targeted therapy for patients with HCC is unsatisfactory because of the complexity of $\mathrm{HCC}^{83}$ The tyrosine kinase inhibitor sorafenib and transarterial chemoembolization are the standard treatments for unresectable HCC, ${ }^{84}$ and limited outcomes have been found with new chemotherapy agents, such as nivolumab, stivarga, ramucirumab, cabozantinib, and lenvatinib. However, all treatment options mentioned above have only a modest effect on
HCC. In addition, many studies have found that HCC development involves modifications in various genes and signaling pathways with heterogenetic characteristics. ${ }^{85}$ Therefore, combination therapy may be the most effective potential stratagem for the treatment of patients with $\mathrm{HCC} .{ }^{86}$ In addition to targeting a single gene for HCC treatment, targeting FGF19 and AR/EGFR in combination may enhance therapeutic efficacy. ${ }^{36}$ With deep mining on various cell lines through miRNA and mRNA sequencing, FGF19 amplification in HCC is characteristic of a proliferation type with good response to an FGFR4 inhibitor. ${ }^{87}$ This study $^{87}$ also found 11 of 34 cell lines (32\%) with FGF19 amplification, including HCC.1.2, SNU387, SNU475, Huh7, Li7, JHH7, SNU354, SNU739, SNU761, SNU878, and SNU886, and provided molecular characteristics and potential drug response predictions. This study, along with an additional clinical review, ${ }^{88}$ suggests choosing different treatment strategies based on the molecular subtype of HCC.

Different targeted inhibitors can be used together, including FGF19 or FGFR4 inhibitors and chemotherapy, to change tumor cell proliferation and differentiation. Gao et $\mathrm{al}^{56}$ found that co-treatment of ponatinib and sorafenib might be an effective therapeutic approach to eradicate sorafenib-resistant HCC. In addition, blocking the FGF19FGFR4 axis might improve the efficacy of sorafenib for the treatment of $\mathrm{HCC}^{89}$ Another study found that the cyclin-dependent kinase 4/6 inhibitor palbociclib, in combination with the selective FGFR4 inhibitor H3B-6527, could significantly reduce tumor development in a xenograft model of HCC. ${ }^{90}$

Immune therapy in combination with targeting therapy to FGF19, FGFR4, and other chemotherapy might be another effective therapeutic option. Immunity plays a vital role in carcinogenesis, including HCC development. Anti-programmed cell death 1 (PD-1), and anti-programmed cell death ligand 1(PD-L1), are some of the most studied immune therapy targets for various tumors. Ectopic FGF19 expression can promote EMT and invasion in epithelial-like HCC cells through repression of E-cadherin expression. Therefore, FGF19 can act as an EMT inducer to exert its tumor-progressing function in addition to promoting proliferation and suppressing anti-HCC immune function. Therefore, inhibiting FGF19 signaling may increase the efficacy of immunotherapy in HCC by suppressing tumor cell immune evasion.

Before selecting specific treatment modalities, molecular diagnosis of the HCC phenotype should be determined to increase treatment efficiency, especially for cold tumors with immunotherapy escape characteristics; for example, $\beta$ catenin activation leads to anti-PD-1-resistant HCC. ${ }^{91}$ In addition, a recent clinical trial found that the combined application of the PD-L1 antibody atezolizumab and the vascular endothelial growth factor antibody bevacizumab had clinical efficacy in patients with unresectable HCC. ${ }^{92}$ Because FGF19 can regulate $\beta$-catenin and Stat3/IL-6, it is difficult to predict the effect of combining an FGF19 
inhibitor and anti-PD-1 chemotherapy on patients with HCC and FGF19 amplification (Figure 4). Meanwhile, on the basis of the FGF19 expression and OS correlation analysis from TCGA database, the group with higher FGF19 expression had lower OS in stage I HCC, no difference in stage 2 and $3 \mathrm{HCC}$, and had higher OS in stage 4 for the higher FGF19 expression HCC. Therefore, further studies are warranted to determine whether this combination strategy would be effective in the treatment of HCC.

\section{Conclusions and Future Prospects}

Under normal conditions, FGF19 functions as a postprandial hormone to regulate hepatic protein synthesis, glycogen synthesis, and gluconeogenesis, and adjusting BA homeostasis. ${ }^{93}$ BAs are regulators of lipid and glucose metabolism and modulate inflammation in the liver. BA can increase the expression of FGF19 through activating FXR. As a consequence, the activated FGF19 can produce negative feedback on BA synthesis in homeostasis to prevent accumulation of toxic BA in human livers via repressing transcription of CYP7A1 in a SHP-dependent manner ${ }^{94}$ or SHP-independent manner. ${ }^{95}$ Meanwhile, FGF19 also stops the gallbladder from filling with bile. ${ }^{94}$ Besides regulating the global BA production level, FGF19-FGFR4- $\beta$-klotho-negative feedback also influences BA composition. FGF19 overexpressed in mice leads to the shift of BA synthesis from the classic pathway (CYP7A1 as the ratelimiting and major regulatory enzyme) to the alternative BA synthesis pathway (cholesterol is converted to chenodeoxycholic acid). Its ortholog Fgf15, in the intestinal response to $\mathrm{BA}$, had a similar function in mice. ${ }^{96}$

BA and FGF19 expression has a negative feedback regulation. FGF19 has lower expression in the liver but higher expression during cholestasis, and high-level BA is associated liver cirrhosis, which will develop into HCC progression. Therefore, the precise feedback negative regulation loop might be broken under some specific conditions during HCC development, leading to later-stage HCC. Patients with the higher FGF19 expression have better OS because FGF19 can regulate BA synthesis, and results in patients with stage I HCC are not different. In addition, the feedback negative regulation loop also provides a clue on how to screen the expression of BA and FGF19 in patients with HCC before using FGF19 targeting as a therapeutic method. Several studies show that selecting a specific FGF19 variant with nontumor function might be useful when targeting FGF19-involved HCC without adverse effects on BA homeostasis when completing binding to FGFR $4 .^{74,97}$ While a specific inhibitor can decrease FGF19 expression in the liver, can nontumor functional FGF19 analog can also be used to reduce FGF19-FGFR4 activated in HCC.

Under abnormal physical conditions, careful evaluation of targetin FGF19 is important to estimate its potential therapeutic values. Although human $F G F 19$ and mice $F g f 15$ are identical genes, FGF19 and $F g f 15$ has big differences based on structure and molecular biology. Fgf15 increases the hydrophilic BA pool in rodents, whereas FGF19 increases hydrophobic BA in humans. In mice, there is no FGFR4 for Fgf15. Such differences can provide us a chance to explore the role of FGF19 in mice, especially to evaluate the therapeutic effective and safety of FGF19 analogous agents or inhibitors in the HCC population with FGF19 amplification. Under normal conditions, FGF19 is expressed in the small intestine and at very low concentration in the liver. FGF21 is expressed in the liver. Such phenomena might be attributable to a negative regulation of FGF19 in the adult liver and up-regulated FGF19 in HCC development. Determination of whether there is any compensatory effect of tumor cell proliferation and metastasis can also provide a direction for further study.

Studies on the molecular mechanism of FGF19 amplification signature in HCC provided additional potential targets for HCC treatment, including GSK3 $\beta$ and Nrf2 inhibitor, ${ }^{56}$ autophagy, and mammalian target of rapamycin complex 1 inhibitor. In one of the HCC mice models, upregulated FGF19 appeared to reduce tumor cell autophagy by increasing mechanistic target of rapamycin expression (Z. Chen et al, unpublished data). In addition, several studies have found that epigenetic changes are also involved in HCC development because of FGF19 amplification. In HCC, overexpression of FGF19/FGFR4 significantly correlates with epithelial cell adhesion molecular expression, which is a marker of hepatic cancer stem cells within the fatty liver-steatosis-cirrhosis-HCC sequence. ${ }^{98}$ SNHG16 is up-regulated and associated with poor prognosis in HCC and increases liver cancer cell proliferation via the miR302a-3p/FGF19 axis. $^{99}$ As mentioned above, different bioinformatic analysis platforms and tools can be used to explore FGF19 tumor-driver patterns and look for potential transcription-binding factors as novel therapeutic targets. In addition, further clinical studies on the efficacy of combination therapy for the treatment of HCC are needed.

In conclusion, FGF19 can be a potential biomarker for primary HCC diagnosis and therapy response. ${ }^{11}$ FGF19 and its receptor FGFR4 and the signaling pathways involved in its activation, including EGFR, wnt $/ \beta$-catenin, ERK, and Stat3/IL-6, can also be novel therapeutic targets for the treatment of HCC. Combination therapy strategies with immune check point inhibitors may be designed from the comprehensive analysis of FGF19 expression level and patterns in different HCC populations.

\section{Acknowledgment}

We thank Dr Satdarshan (Paul) Singh Monga from University of Pittsburgh and Dr Xin Chen from University of California, San Francisco for the unpublished animal model study. 


\section{Authors Contributions}

Z.G.C. performed literature search and prepared the manuscript; L.L.J. prepared the section on signal pathway; L.F.L. helped perform the ChIP-seq and ATAC-seq analysis and wrote the section on the role of FGF19 amplification on chromatin accessibility; K.K. and Q.Z. revised the manuscript; L.Z. addressed comments and contributed to writing; S.J.L. wrote the section on FGF19 as HCC driver partner and critically reviewed of the manuscript; J.Y.T. collected literature data, and drafted and critically revised the of manuscript. All authors read and approved the final manuscript.

\section{References}

1. Llovet JM, Bruix J: Novel advancements in the management of hepatocellular carcinoma in 2008. J Hepatol 2008, 48 Suppl 1:S20-S37

2. Llovet JM, Ricci S, Mazzaferro V, Hilgard P, Gane E, Blanc JF, de Oliveira AC, Santoro A, Raoul JL, Forner A, Schwartz M, Porta C, Zeuzem S, Bolondi L, Greten TF, Galle PR, Seitz JF, Borbath I, Haussinger D, Giannaris T, Shan M, Moscovici M, Voliotis D, Bruix J, Group SIS: Sorafenib in advanced hepatocellular carcinoma. N Engl J Med 2008, 359:378-390

3. Killock D: Liver cancer: regorafenib - a new resource in HCC. Nat Rev Clin Oncol 2017, 14:70-71

4. Raja A, Park I, Haq F, Ahn SM: FGF19-FGFR4 signaling in hepatocellular carcinoma. Cells 2019, 8:536

5. Ornitz DM, Itoh N: Fibroblast growth factors. Genome Biol 2001, 2. REVIEWS3005

6. Elzi DJ, Song M, Blackman B, Weintraub ST, Lopez-Terrada D, Chen Y, Tomlinson GE, Shiio Y: FGF19 functions as autocrine growth factor for hepatoblastoma. Genes Cancer 2016, 7:125-135

7. Arnold A, Bahra M, Lenze D, Bradtmoller M, Guse K, Gehlhaar C, Blaker H, Heppner FL, Koch A: Genome wide DNA copy number analysis in cholangiocarcinoma using high resolution molecular inversion probe single nucleotide polymorphism assay. Exp Mol Pathol 2015, 99:344-353

8. Hartmann P, Hochrath K, Horvath A, Chen P, Seebauer CT, Llorente C, Wang L, Alnouti Y, Fouts DE, Starkel P, Loomba R, Coulter S, Liddle C, Yu RT, Ling L, Rossi SJ, DePaoli AM, Downes M, Evans RM, Brenner DA, Schnabl B: Modulation of the intestinal bile acid/farnesoid $\mathrm{X}$ receptor/fibroblast growth factor 15 axis improves alcoholic liver disease in mice. Hepatology 2018, 67: $2150-2166$

9. Maeda T, Kanzaki H, Chiba T, Ao J, Kanayama K, Maruta S, Kusakabe Y, Saito T, Kobayashi K, Kiyono S, Nakamura M, Ogasawara S, Suzuki E, Ooka Y, Nakamoto S, Nakagawa R, Muroyama R, Kanda T, Maruyama H, Kato N: Serum fibroblast growth factor 19 serves as a potential novel biomarker for hepatocellular carcinoma. BMC Cancer 2019, 19:1088

10. Liu WY, Xie DM, Zhu GQ, Huang GQ, Lin YQ, Wang LR, Shi KQ, Hu B, Braddock M, Chen YP, Zheng MH: Targeting fibroblast growth factor 19 in liver disease: a potential biomarker and therapeutic target. Expert Opin Ther Targets 2015, 19:675-685

11. Kaibori M, Sakai K, Ishizaki M, Matsushima H, De Velasco MA, Matsui K, Iida H, Kitade H, Kwon AH, Nagano H, Wada H, Haji S, Tsukamoto T, Kanazawa A, Takeda Y, Takemura S, Kubo S, Nishio K: Increased FGF19 copy number is frequently detected in hepatocellular carcinoma with a complete response after sorafenib treatment. Oncotarget 2016, 7:49091-49098

12. Arao T, Ueshima K, Matsumoto K, Nagai T, Kimura H, Hagiwara S, Sakurai T, Haji S, Kanazawa A, Hidaka H, Iso Y, Kubota K,
Shimada M, Utsunomiya T, Hirooka M, Hiasa Y, Toyoki Y, Hakamada K, Yasui K, Kumada T, Toyoda H, Sato S, Hisai H, Kuzuya T, Tsuchiya K, Izumi N, Arii S, Nishio K, Kudo M: FGF3/FGF4 amplification and multiple lung metastases in responders to sorafenib in hepatocellular carcinoma. Hepatology 2013, 57: $1407-1415$

13. Knights V, Cook SJ: De-regulated FGF receptors as therapeutic targets in cancer. Pharmacol Ther 2010, 125:105-117

14. Beenken A, Mohammadi M: The FGF family: biology, pathophysiology and therapy. Nat Rev Drug Discov 2009, 8:235-253

15. Turner N, Grose R: Fibroblast growth factor signalling: from development to cancer. Nat Rev Cancer 2010, 10:116-129

16. Alvarez-Sola G, Uriarte I, Latasa MU, Jimenez M, BarcenaVarela M, Santamaria E, Urtasun R, Rodriguez-Ortigosa C, Prieto J, Corrales FJ, Baulies A, Garcia-Ruiz C, Fernandez-Checa JC, Berraondo P, Fernandez-Barrena MG, Berasain C, Avila MA: Engineered fibroblast growth factor 19 protects from acetaminopheninduced liver injury and stimulates aged liver regeneration in mice. Cell Death Dis 2017, 8:e3083

17. Zhou M, Learned RM, Rossi SJ, DePaoli AM, Tian H, Ling L: Engineered fibroblast growth factor 19 reduces liver injury and resolves sclerosing cholangitis in Mdr2-deficient mice. Hepatology 2016, 63:914-929

18. Nicholes K, Guillet S, Tomlinson E, Hillan K, Wright B, Frantz GD, Pham TA, Dillard-Telm L, Tsai SP, Stephan JP, Stinson J, Stewart T, French DM: A mouse model of hepatocellular carcinoma: ectopic expression of fibroblast growth factor 19 in skeletal muscle of transgenic mice. Am J Pathol 2002, 160: 2295-2307

19. Wu X, Ge H, Lemon B, Vonderfecht S, Weiszmann J, Hecht R, Gupte J, Hager T, Wang Z, Lindberg R, Li Y: FGF19-induced hepatocyte proliferation is mediated through FGFR4 activation. J Biol Chem 2010, 285:5165-5170

20. Zhou M, Luo J, Chen M, Yang H, Learned RM, DePaoli AM, Tian H, Ling L: Mouse species-specific control of hepatocarcinogenesis and metabolism by FGF19/FGF15. J Hepatol 2017, 66: $1182-1192$

21. Naugler WE, Tarlow BD, Fedorov LM, Taylor M, Pelz C, Li B, Darnell J, Grompe M: Fibroblast growth factor signaling controls liver size in mice with humanized livers. Gastroenterology 2015, 149 : 728-740.e15

22. Dailey L, Ambrosetti D, Mansukhani A, Basilico C: Mechanisms underlying differential responses to FGF signaling. Cytokine Growth Factor Rev 2005, 16:233-247

23. Zhao HK, Lv FL, Liang GZ, Huang XB, Wu G, Zhang WF, Yu L, Shi L, Teng Y: FGF19 promotes epithelial-mesenchymal transition in hepatocellular carcinoma cells by modulating the GSK3 beta/betacatenin signaling cascade via FGFR4 activation. Oncotarget 2016, 7:13575-13586

24. Teng Y, Zhao HK, Gao LX, Zhang WF, Shull AY, Shay C: FGF19 protects hepatocellular carcinoma cells against endoplasmic reticulum stress via activation of FGFR4-GSK3 beta-Nrf2 signaling. Cancer Res 2017, 77:6215-6225

25. Ahn SM, Jang SJ, Shim JH, Kim D, Hong SM, Sung CO, Baek D, Haq F, Ansari AA, Lee SY, Chun SM, Choi S, Choi HJ, Kim J, Kim S, Hwang S, Lee YJ, Lee JE, Jung WR, Jang HY, Yang E, Sung WK, Lee NP, Mao M, Lee C, Zucman-Rossi J, Yu E, Lee HC, Kong G: Genomic portrait of resectable hepatocellular carcinomas: implications of RB1 and FGF19 aberrations for patient stratification. Hepatology 2014, 60:1972-1982

26. Liu J, Fan L, Yu H, Zhang J, He Y, Feng D, Wang F, Li X, Liu Q, Li Y, Guo Z, Gao B, Wei W, Wang H, Sun G: Endoplasmic reticulum stress causes liver cancer cells to release exosomal miR-23a-3p and up-regulate programmed death ligand 1 expression in macrophages. Hepatology 2019, 70:241-258

27. Cui G, Martin RC, Jin H, Liu X, Pandit H, Zhao H, Cai L, Zhang P, Li W, Li Y: Up-regulation of FGF15/19 signaling promotes 
hepatocellular carcinoma in the background of fatty liver. J Exp Clin Cancer Res 2018, 37:136

28. Wunsch E, Milkiewicz M, Wasik U, Trottier J, KempinskaPodhorodecka A, Elias E, Barbier O, Milkiewicz P: Expression of hepatic fibroblast growth factor 19 is enhanced in primary biliary cirrhosis and correlates with severity of the disease. Sci Rep 2015, 5:13462

29. Xiao B, Cui LM, Ma DJ, Liu SP, Zhang XW: Endoplasmic reticulum stress in diethylnitrosamine-induced rat liver cancer. Oncol Lett 2014, 7:23-27

30. Zhou M, Yang H, Learned RM, Tian H, Ling L: Non-cell-autonomous activation of IL-6/STAT3 signaling mediates FGF19-driven hepatocarcinogenesis. Nat Commun 2017, 8:15433

31. Calvisi DF, Ladu S, Gorden A, Farina M, Conner EA, Lee JS, Factor VM, Thorgeirsson SS: Ubiquitous activation of Ras and Jak/Stat pathways in human HCC. Gastroenterology 2006, 130: $1117-1128$

32. Kurosu H, Choi M, Ogawa Y, Dickson AS, Goetz R, Eliseenkova AV, Mohammadi M, Rosenblatt KP, Kliewer SA, Kuroo M: Tissue-specific expression of betaKlotho and fibroblast growth factor (FGF) receptor isoforms determines metabolic activity of FGF19 and FGF21. J Biol Chem 2007, 282:26687-26695

33. Lin BC, Wang M, Blackmore C, Desnoyers LR: Liver-specific activities of FGF19 require Klotho beta. J Biol Chem 2007, 282: 27277-27284

34. Kir S, Beddow SA, Samuel VT, Miller P, Previs SF, Suino-Powell K, $\mathrm{Xu}$ HE, Shulman GI, Kliewer SA, Mangelsdorf DJ: FGF19 as a postprandial, insulin-independent activator of hepatic protein and glycogen synthesis. Science 2011, 331:1621-1624

35. Castillo J, Goni S, Latasa MU, Perugorria MJ, Calvo A, Muntane J, Bioulac-Sage P, Balabaud C, Prieto J, Avila MA, Berasain C: Amphiregulin induces the alternative splicing of p73 into its oncogenic isoform DeltaEx2p73 in human hepatocellular tumors. Gastroenterology 2009, 137:1805-18015.e1-4

36. Latasa MU, Salis F, Urtasun R, Garcia-Irigoyen O, Elizalde M, Uriarte I, Santamaria M, Feo F, Pascale RM, Prieto J, Berasain C, Avila MA: Regulation of amphiregulin gene expression by betacatenin signaling in human hepatocellular carcinoma cells: a novel crosstalk between FGF19 and the EGFR system. PLoS One 2012, 7: e52711

37. Handen A, Ganapathiraju MK: LENS: web-based lens for enrichment and network studies of human proteins. BMC Med Genomics 2015, 8 Suppl 4:S2

38. Patel NS, Rhinn M, Semprich CI, Halley PA, Dolle P, Bickmore WA, Storey KG: FGF signalling regulates chromatin organisation during neural differentiation via mechanisms that can be uncoupled from transcription. PLoS Genet 2013, 9:e1003614

39. Lachmann A, Xu H, Krishnan J, Berger SI, Mazloom AR, Ma'ayan A: ChEA: transcription factor regulation inferred from integrating genome-wide ChIP-X experiments. Bioinformatics 2010, 26:2438-2444

40. Kuleshov MV, Jones MR, Rouillard AD, Fernandez NF, Duan Q, Wang Z, Koplev S, Jenkins SL, Jagodnik KM, Lachmann A, McDermott MG, Monteiro CD, Gundersen GW, Ma'ayan A: Enrichr: a comprehensive gene set enrichment analysis web server 2016 update. Nucleic Acids Res 2016, 44:W90-W97

41. Porta-Pardo E, Garcia-Alonso L, Hrabe T, Dopazo J, Godzik A: A pan-cancer catalogue of cancer driver protein interaction interfaces. PLoS Comput Biol 2015, 11:e1004518

42. Potthoff MJ, Boney-Montoya J, Choi M, He T, Sunny NE, Satapati S, Suino-Powell K, Xu HE, Gerard RD, Finck BN, Burgess SC, Mangelsdorf DJ, Kliewer SA: FGF15/19 regulates hepatic glucose metabolism by inhibiting the CREB-PGC-1alpha pathway. Cell Metab 2011, 13:729-738

43. Kim YC, Seok S, Byun S, Kong B, Zhang Y, Guo G, Xie W, Ma J, Kemper B, Kemper JK: AhR and SHP regulate phosphatidylcholine and S-adenosylmethionine levels in the one-carbon cycle. Nat Commun 2018, 9:540
44. Hatch NE, Li Y, Franceschi RT: FGF2 stimulation of the pyrophosphate-generating enzyme, PC-1, in pre-osteoblast cells is mediated by RUNX2. J Bone Miner Res 2009, 24:652-662

45. Miyata M, Hata T, Yamazoe Y, Yoshinari K: SREBP-2 negatively regulates FXR-dependent transcription of FGF19 in human intestinal cells. Biochem Biophys Res Commun 2014, 443:477-482

46. Cancer Genome Atlas Research Network. Electronic address: wheeler@bcm.edu, Cancer Genome Atlas Research Network: Comprehensive and integrative genomic characterization of hepatocellular carcinoma. Cell 2017, 169:1327-1341.e23

47. Cerami E, Gao J, Dogrusoz U, Gross BE, Sumer SO, Aksoy BA, Jacobsen A, Byrne CJ, Heuer ML, Larsson E, Antipin Y, Reva B, Goldberg AP, Sander C, Schultz N: The cBio cancer genomics portal: an open platform for exploring multidimensional cancer genomics data. Cancer Discov 2012, 2:401-404

48. Sawey ET, Chanrion M, Cai C, Wu G, Zhang J, Zender L, Zhao A, Busuttil RW, Yee H, Stein L, French DM, Finn RS, Lowe SW, Powers S: Identification of a therapeutic strategy targeting amplified FGF19 in liver cancer by oncogenomic screening. Cancer Cell 2011, 19:347-358

49. Chen X, Calvisi DF: Hydrodynamic transfection for generation of novel mouse models for liver cancer research. Am J Pathol 2014, 184 912-923

50. Cancer Genome Atlas Research Network: Comprehensive genomic characterization defines human glioblastoma genes and core pathways. Nature 2008, 455:1061-1068

51. Vandin F, Upfal E, Raphael BJ: De novo discovery of mutated driver pathways in cancer. Genome Res 2012, 22:375-385

52. Lu S, Lu KN, Cheng SY, Hu B, Ma X, Nystrom N, Lu X: Identifying driver genomic alterations in cancers by searching minimum-weight, mutually exclusive sets. PLoS Comput Biol 2015, 11:e1004257

53. Kim YA, Madan S, Przytycka TM: WeSME: uncovering mutual exclusivity of cancer drivers and beyond. Bioinformatics 2017, 33 . 814-821

54. Lu S, Cai C, Yan G, Zhou Z, Wan Y, Chen V, Chen L, Cooper GF, Obeid LM, Hannun YA, Lee AV, Lu X: Signal-oriented pathway analyses reveal a signaling complex as a synthetic lethal target for $\mathrm{p} 53$ mutations. Cancer Res 2016, 76:6785-6794

55. Cai C, Cooper GF, Lu KN, Ma X, Xu S, Zhao Z, Chen X, Xue Y, Lee AV, Clark N, Chen V, Lu S, Chen L, Yu L, Hochheiser HS, Jiang X, Wang QJ, Lu X: Systematic discovery of the functional impact of somatic genome alterations in individual tumors through tumor-specific causal inference. PLoS Comput Biol 2019, 15: e1007088

56. Gao L, Wang X, Tang Y, Huang S, Hu CA, Teng Y: FGF19/FGFR4 signaling contributes to the resistance of hepatocellular carcinoma to sorafenib. J Exp Clin Cancer Res 2017, 36:8

57. Repana D, Ross P: Targeting FGF19/FGFR4 pathway: a novel therapeutic strategy for hepatocellular carcinoma. Diseases 2015, 3: 294-305

58. Yang Y, Zhou Y, Lu M, An Y, Li R, Chen Y, Lu DR, Jin L, Zhou WP, Qian J, Wang HY: Association between fibroblast growth factor receptor 4 polymorphisms and risk of hepatocellular carcinoma. Mol Carcinog 2012, 51:515-521

59. Wu X, Ge H, Lemon B, Vonderfecht S, Baribault H, Weiszmann J, Gupte J, Gardner J, Lindberg R, Wang Z, Li Y: Separating mitogenic and metabolic activities of fibroblast growth factor 19 (FGF19). Proc Natl Acad Sci U S A 2010, 107:14158-14163

60. Wu AL, Coulter S, Liddle C, Wong A, Eastham-Anderson J, French DM, Peterson AS, Sonoda J: FGF19 regulates cell proliferation, glucose and bile acid metabolism via FGFR4-dependent and independent pathways. PLoS One 2011, 6:e17868

61. Desnoyers LR, Pai R, Ferrando RE, Hotzel K, Le T, Ross J, Carano R, D'Souza A, Qing J, Mohtashemi I, Ashkenazi A, French DM: Targeting FGF19 inhibits tumor growth in colon cancer xenograft and FGF19 transgenic hepatocellular carcinoma models. Oncogene 2008, 27:85-97 
62. Liu Y, Cao M, Cai Y, Li X, Zhao C, Cui R: Dissecting the role of the FGF19-FGFR4 signaling pathway in cancer development and progression. Front Cell Dev Biol 2020, 8:95

63. French DM, Lin BC, Wang M, Adams C, Shek T, Hotzel K, Bolon B, Ferrando R, Blackmore C, Schroeder K, Rodriguez LA, Hristopoulos M, Venook R, Ashkenazi A, Desnoyers LR: Targeting FGFR4 inhibits hepatocellular carcinoma in preclinical mouse models. PLoS One 2012, 7:e36713

64. Bartz R, Fukuchi K, Ohtsuka T, Lange T, Gruner K, Watanabe I, Hayashi S, Oda Y, Kawaida R, Komori H, Kashimoto Y, Wirtz P, Mayer JA, Redondo-Muller M, Saito S, Takahashi M, Hanzawa H, Imai E, Martinez A, Hanai M, Haussinger D, Chapman RW, Agatsuma T, Bange J, Abraham R: Preclinical development of U31784, a novel FGFR4 antibody against cancer, and avoidance of its on-target toxicity. Mol Cancer Ther 2019, 18:1832-1843

65. Huang X, Yang C, Jin C, Luo Y, Wang F, McKeehan WL: Resident hepatocyte fibroblast growth factor receptor 4 limits hepatocarcinogenesis. Mol Carcinog 2009, 48:553-562

66. Hagel M, Miduturu C, Sheets M, Rubin N, Weng W, Stransky N, Bifulco N, Kim JL, Hodous B, Brooijmans N, Shutes A, Winter C, Lengauer C, Kohl NE, Guzi T: First selective small molecule inhibitor of FGFR4 for the treatment of hepatocellular carcinomas with an activated FGFR4 signaling pathway. Cancer Discov 2015, 5: 424-437

67. Matsuki M, Hoshi T, Yamamoto Y, Ikemori-Kawada M, Minoshima Y, Funahashi Y, Matsui J: Lenvatinib inhibits angiogenesis and tumor fibroblast growth factor signaling pathways in human hepatocellular carcinoma models. Cancer Med 2018, 7: $2641-2653$

68. Kim RD, Sarker D, Meyer T, Yau T, Macarulla T, Park JW, Choo SP, Hollebecque A, Sung MW, Lim HY, Mazzaferro V, Trojan J, Zhu AX, Yoon JH, Sharma S, Lin ZZ, Chan SL, Faivre S, Feun LG, Yen CJ, Dufour JF, Palmer DH, Llovet JM, Manoogian M, Tugnait M, Stransky N, Hagel M, Kohl NE, Lengauer C, Sherwin CA, Schmidt-Kittler O, Hoeflich KP, Shi H, Wolf BB, Kang YK: First-in-human phase I study of fisogatinib (BLU-554) validates aberrant FGF19 signaling as a driver event in hepatocellular carcinoma. Cancer Discov 2019, 9:1696-1707

69. Kim YC, Byun S, Zhang Y, Seok S, Kemper B, Ma J, Kemper JK: Liver ChIP-seq analysis in FGF19-treated mice reveals SHP as a global transcriptional partner of SREBP-2. Genome Biol 2015, 16: 268

70. Cai SY, He H, Nguyen T, Mennone A, Boyer JL: Retinoic acid represses CYP7A1 expression in human hepatocytes and HepG2 cells by FXR/RXR-dependent and independent mechanisms. J Lipid Res 2010, 51:2265-2274

71. Xu W, Wang Y, Guo Y, Liu J, Ma L, Cao W, Yu B, Zhou Y: Fibroblast growth factor 19 improves cardiac function and mitochondrial energy homoeostasis in the diabetic heart. Biochem Biophys Res Commun 2018, 505:242-248

72. Shih DM, Kast-Woelbern HR, Wong J, Xia YR, Edwards PA, Lusis AJ: A role for FXR and human FGF-19 in the repression of paraoxonase-1 gene expression by bile acids. J Lipid Res 2006, 47: 384-392

73. Li Z, Lin B, Lin G, Wu Y, Jie Y, Li X, Ko B, Chong Y, Luo J: Circulating FGF19 closely correlates with bile acid synthesis and cholestasis in patients with primary biliary cirrhosis. PLoS One 2017, 12:e0178580

74. Gadaleta RM, Scialpi N, Peres C, Cariello M, Ko B, Luo J, Porru E, Roda A, Sabba C, Moschetta A: Suppression of hepatic bile acid synthesis by a non-tumorigenic FGF19 analogue protects mice from fibrosis and hepatocarcinogenesis. Sci Rep 2018, 8:17210

75. Avila MA, Moschetta A: The FXR-FGF19 gut-liver axis as a novel "hepatostat". Gastroenterology 2015, 149:537-540

76. Piglionica M, Cariello M, Moschetta A: The gut-liver axis in hepatocarcinoma: a focus on the nuclear receptor FXR and the enterokine FGF19. Curr Opin Pharmacol 2018, 43:93-98
77. Miyata M, Hata T, Yamakawa H, Kagawa T, Yoshinari K, Yamazoe Y: Involvement of multiple elements in FXR-mediated transcriptional activation of FGF19. J Steroid Biochem Mol Biol 2012, 132:41-47

78. Degirolamo C, Sabba C, Moschetta A: Therapeutic potential of the endocrine fibroblast growth factors FGF19, FGF21 and FGF23. Nat Rev Drug Discov 2016, 15:51-69

79. Tamimi Y, Skarie JM, Footz T, Berry FB, Link BA, Walter MA: FGF19 is a target for FOXC1 regulation in ciliary body-derived cells. Hum Mol Genet 2006, 15:3229-3240

80. Huang $\mathrm{S}, \mathrm{He} \mathrm{X}$ : The role of microRNAs in liver cancer progression. Br J Cancer 2011, 104:235-240

81. Fu T, Choi SE, Kim DH, Seok S, Suino-Powell KM, Xu HE, Kemper JK: Aberrantly elevated microRNA-34a in obesity attenuates hepatic responses to FGF19 by targeting a membrane coreceptor betaKlotho. Proc Natl Acad Sci U S A 2012, 109:16137-16142

82. Fu T, Kemper JK: MicroRNA-34a and impaired FGF19/21 signaling in obesity. Vitam Horm 2016, 101:175-196

83. Nakagawa H, Fujita M, Fujimoto A: Genome sequencing analysis of liver cancer for precision medicine. Semin Cancer Biol 2019, 55: $120-127$

84. Li H, Li S, Geng J, Zhao S, Tan K, Yang Z, Feng D, Liu L: Efficacy evaluation of the combination therapy of sorafenib and transarterial chemoembolization for unresectable HCC: a systematic review and meta-analysis of comparative studies. Ann Transl Med 2020, 8:540

85. Schmidt C, Marsh JW: Molecular signature for HCC: role in predicting outcomes after liver transplant and selection for potential adjuvant treatment. Curr Opin Organ Transplant 2010, 15:277-282

86. Pinyol R, Montal R, Bassaganyas L, Sia D, Takayama T, Chau GY, Mazzaferro V, Roayaie S, Lee HC, Kokudo N, Zhang Z, Torrecilla S, Moeini A, Rodriguez-Carunchio L, Gane E, Verslype C, Croitoru AE, Cillo U, de la Mata M, Lupo L, Strasser S, Park JW, Camps J, Sole M, Thung SN, Villanueva A, Pena C, Meinhardt G, Bruix J, Llovet JM: Molecular predictors of prevention of recurrence in HCC with sorafenib as adjuvant treatment and prognostic factors in the phase 3 STORM trial. Gut 2019, 68:1065-1075

87. Caruso S, Calatayud AL, Pilet J, La Bella T, Rekik S, Imbeaud S, Letouze E, Meunier L, Bayard Q, Rohr-Udilova N, Peneau C, GraslKraupp B, de Koning L, Ouine B, Bioulac-Sage P, Couchy G, Calderaro J, Nault JC, Zucman-Rossi J, Rebouissou S: Analysis of liver cancer cell lines identifies agents with likely efficacy against hepatocellular carcinoma and markers of response. Gastroenterology 2019, 157:760-776

88. Llovet JM, Hernandez-Gea V: Hepatocellular carcinoma: reasons for phase III failure and novel perspectives on trial design. Clin Cancer Res 2014, 20:2072-2079

89. Gao L, Shay C, Lv F, Wang X, Teng Y: Implications of FGF19 on sorafenib-mediated nitric oxide production in hepatocellular carcinoma cells - a short report. Cell Oncol (Dordr) 2018, 41:85-91

90. Joshi JJ, Coffey H, Corcoran E, Tsai J, Huang CL, Ichikawa K, Prajapati S, Hao MH, Bailey S, Wu J, Rimkunas V, Karr C, Subramanian V, Kumar P, MacKenzie C, Hurley R, Satoh T, Yu K, Park E, Rioux N, Kim A, Lai WG, Yu L, Zhu P, Buonamici S, Larsen N, Fekkes P, Wang J, Warmuth M, Reynolds DJ, Smith PG, Selvaraj A: H3B-6527 is a potent and selective inhibitor of FGFR4 in FGF19-driven hepatocellular carcinoma. Cancer Res 2017, 77: 6999-7013

91. Ruiz de Galarreta M, Bresnahan E, Molina-Sanchez P, Lindblad KE, Maier B, Sia D, Puigvehi M, Miguela V, Casanova-Acebes M, Dhainaut M, Villacorta-Martin C, Singhi AD, Moghe A, von Felden J, Tal Grinspan L, Wang S, Kamphorst AO, Monga SP, Brown BD, Villanueva A, Llovet JM, Merad M, Lujambio A: beta-Catenin activation promotes immune escape and resistance to anti-PD-1 therapy in hepatocellular carcinoma. Cancer Discov 2019, 9:1124-1141

92. Finn RS, Qin S, Ikeda M, Galle PR, Ducreux M, Kim TY, Kudo M, Breder V, Merle P, Kaseb AO, Li D, Verret W, Xu DZ, Hernandez S, 
Liu J, Huang C, Mulla S, Wang Y, Lim HY, Zhu AX, Cheng AL; IMbrave150 Investigators: Atezolizumab plus bevacizumab in unresectable hepatocellular carcinoma. N Engl J Med 2020, 382:1894-1905

93. Kir S, Kliewer SA, Mangelsdorf DJ: Roles of FGF19 in liver metabolism. Cold Spring Harb Symp Quant Biol 2011, 76:139-144

94. Kliewer SA, Mangelsdorf DJ: Bile acids as hormones: the FXRFGF15/19 pathway. Dig Dis 2015, 33:327-331

95. Song KH, Li T, Owsley E, Strom S, Chiang JY: Bile acids activate fibroblast growth factor 19 signaling in human hepatocytes to inhibit cholesterol 7alpha-hydroxylase gene expression. Hepatology 2009, 49:297-305

96. Inagaki $\mathrm{T}$, Choi $\mathrm{M}$, Moschetta A, Peng L, Cummins CL, McDonald JG, Luo G, Jones SA, Goodwin B, Richardson JA, Gerard RD, Repa JJ, Mangelsdorf DJ, Kliewer SA: Fibroblast growth factor 15 functions as an enterohepatic signal to regulate bile acid homeostasis. Cell Metab 2005, 2:217-225

97. Zhou M, Wang X, Phung V, Lindhout DA, Mondal K, Hsu JY, Yang H, Humphrey M, Ding X, Arora T, Learned RM, DePaoli AM, Tian H, Ling L: Separating tumorigenicity from bile acid regulatory activity for endocrine hormone FGF19. Cancer Res 2014, 74: $3306-3316$

98. Li Y, Zhang W, Doughtie A, Cui G, Li X, Pandit H, Yang Y, Li S, Martin R: Up-regulation of fibroblast growth factor 19 and its receptor associates with progression from fatty liver to hepatocellular carcinoma. Oncotarget 2016, 7:52329-52339

99. Li W, Xu W, Song JS, Wu T, Wang WX: LncRNA SNHG16 promotes cell proliferation through miR-302a-3p/FGF19 axis in hepatocellular carcinoma. Neoplasma 2019, 66:397-404 